Garth Benneyworth

Programme Head, Heritage Studies,

Sol Plaatje University. garth.benneyworth@spu. ac.za

DOI: https://dx.doi. org/10.18820/24150509/ JCH42.v1.2

ISSN 0258-2422 (Print) ISSN 2415-0509 (Online)

Journal for Contemporary History 2017 42(1):23-38

(c) UV/UFS

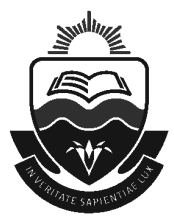

\section{OPERATION MAYIBUYE: PLANS WITHIN PLANS, SPIES AND LIES, 1963}

\begin{abstract}
If ever there is a documented plan that is able to evoke debate and controversy, it is Operation Mayibuye; a military plan seized by the police during a raid at Liliesleaf farm in Rivonia on 11 July 1963. This article examines aspects of this plan in detail, for example who drafted it, what its purpose was, whether it was ever approved and, if so, by whom? Other questions explored include whether it remained unapproved at the time of the raid - if so, why, and the number of copies seized by the police at Liliesleaf. This article builds on prior research regarding this plan, which started with an interview in April 2004 with four Rivonia Trial veterans. The mere mention of the Operation Mayibuye Plan unlocked a range of conflicting views, guaranteeing a heated, yet fascinating debate. Evidence was uncovered that the police used the plan to refabricate the evidence seized. Even in the contemporary context, no one seems able to reach universal consensus on the matter, with one exception being that those who were captured at Liliesleaf faced the very real possibility of being hanged for being in possession of it.
\end{abstract}

Keywords: Operation Mayibuye; Liliesleaf; Rivonia; intelligence; Security Branch; spies; Secret Intelligence Service; Central Intelligence Agency $(\mathrm{ClA})$.

Sleutelwoorde: Operasie Mayibuye; Liliesleaf; Rivonia; intelligensie; Veiligheidstak; spioene; Geheime Intellligensiediens; Central Intelligence Agency (CIA).

\section{ORIGIN OF THE PLAN}

The plan was written during the second half of 1962, after Nelson Mandela's arrest in August of that year. It emerged within a context of certain frustrations about the extent to which a sabotage campaign could in effect successfully challenge and topple the apartheid state. The sabotage campaign, which started in 1961, unleashed stronger repressive reactions from the state and more arrests, and this seriously affected Umkhonto we Sizwe (MK)'s activities by 1962. Though the High Command believed that sabotage was a necessary starting point, it was more and more contemplated that it was counterproductive 
and that a broader mass based struggle, using guerilla warfare as one of its phases, could hold greater possibility. Govan Mbeki summed up the mood of the evolving situation. "Sabotage activities were not proving very successful. So I get to Joburg. We meet as a National High Command and I said, Comrades, let's take it a step further. The sabotage fails. It's frustrating in fact. It's no longer successful, and we think this is going to peter out, peter out and we can't allow that. Let's get on to the next phase, which is the armed struggle itself. Then we considered that. They said, 'You go and draw up a document.' So Joe Slovo and myself were instructed to go and draw up a document on how it was to be done."1 Goldreich later said that, following discussion amongst some groups in MK, he was also asked to draw up a similar document for submission to the National High Command. ${ }^{2}$

Bob Hepple recalled that, "The plan which emerged was premised on mass revolutionary action which needed to be sparked off by organised and well prepared guerilla actions, using the Cuban/Fidel Castro model. This was the era of Che (Guevara) and Cuba, which was incredibly influential. There were those who believed that a flame would ignite the masses". ${ }^{3}$ The plan foresaw rapid progress to semi-conventional warfare. South African Communist Party (SACP) strategists were convinced that the apartheid state would not last long. ${ }^{4}$ This was a serious underestimation of the capacity of the political and security apartheid establishment.

As part of the plan, MK members, trained outside the Republic, would be deployed. ${ }^{5}$ Operation Mayibuye called for four groups of 30 people each to land simultaneously by sea or air inside the Republic before splitting up into platoons of ten persons each, establishing base areas inside guerilla zones. Guerilla units, comprising of 7000 guerillas, would already have been formed and be in position in four pre-designated regions, namely Port Elizabeth to Mzimkulu, Port Shepstone to Swaziland, North-West Transvaal bordering Bechuanaland and Limpopo, and the North-West Cape to South West Africa. The local groups would be 2000 strong in the first three designated areas and 1000 in the fourth. ${ }^{6}$ The plan included a series of logistical proposals together with a recommendation that various departments be established, such as Intelligence, logistics and

1 SADET, The road to democracy in South Africa, Volume 1 (1960-1970) (Cape Town: Zebra Press, 2004), p. 138.

2 T Simpson, Umkhonto we Sizwe. The ANC's armed struggle (Cape Town: Penguin Books, 2016), p. 79.

3 Liliesleaf Archives (LL)/INT 3/LOT 4. G Benneyworth interview with Sir Bob Hepple, Cambridge, 2005 (Transcripts).

4 Stephen Ellis, External mission. The ANC in exile (Johannesburg: Johnathan Ball Publishers Pty Ltd, 2012), p. 37.

$5 \quad$ Ibid., p. 32.

6 Simpson, p. 80. 
transport. It is mentioned in the military element that an unnamed country would assist with the operation.

An appraisal of how these groups might evade detection by the South African military as they approach and enter South African territory, and how the 7000 guerillas assembling inside the country would escape the attention of the South African military, remained noticeably absent from the plan. Nevertheless, Arthur Goldreich and Joe Slovo subsequently presented Operation Mayibuye to the High Command in two sections. This took place at Liliesleaf between the end of the first and the beginning of the second week of May $1963 . .^{7}$ The presentation probably took place inside the thatched cottage, given that the cottage was often used for such discussions by a host of allied organisations, namely the SACP's Central Committee and Secretariat, the African National Congress Executive, and MK with its committees and its regional and high commands. At the conclusion of the presentation, Goldreich pushed for an adoption of the plan, saying that it could be implemented in a relatively short time. ${ }^{8}$

Ahmed Kathrada related in 2004 that, "no matter what anybody says I know that this discussion will go on for eternity. Operation Mayibuye was never ever passed by anybody. The Central Committee had grave reservations about it."

Walter Sisulu has also contested Mbeki's version of events, though Sisulu recalled there being some sympathy for the plan. "We thought no, it's too wild. If you go to Govan he will say Mayibuye was adopted. None of the others will agree to that, we don't agree. It was never approved. It was under discussion when we were arrested at Rivonia."10

Lionel Bernstein also objected. He saw it as a purely technical military document, which set out a military plan. Bernstein had served with the South African Army in combat operations during the Second World War and had, "a total distrust of military thinkers. It didn't make any attempt at providing an analytical strategy for the movement; it provided a military logistical assessment that could have been done at South African Defence Headquarters in Pretoria. It was never endorsed by the Party. On the other hand if you talk to Slovo he'll probably tell you it was, and there were strong objections to it on the Party's Central Committee. Some of the people like Sisulu will tell you the ANC never adopted it." 11

Joe Matthews recalled that at the Central Committee meeting at which the plan was presented, "Govan Mbeki introduced the subject. I challenged him. Ruth First challenged him. In fact Bram Fischer used his favorite swearword. You

\footnotetext{
$7 \quad$ Ibid.

8 Ibid.

9 LL/INT 2. G Benneyworth interview with Ahmed Kathrada, Liliesleaf, 2004.

10 SADET, p. 139.

11 Ibid., pp. 139-140.
} 
know, Bram Fischer couldn't swear. He's such a decent man. But he said, 'Julle is n klomp pampoene (You're a bunch of pumpkin heads)', you know, because, he thought it was so crazy. Mbeki was so angry that he said, 'Ag sies, you are all a bunch of cowards.' And of course Ruth First burst into laughter. The thing was a farce. The meeting was an absolute farce because you didn't have an analysis, you see."12

It remains unknown how many presentations were made. There were at least two discussions about the plan in the Central Committee structure. The first being the joint presentation referred to. The second took place on Saturday 6 July 1963 , by which stage Slovo had left the country with a copy of the plan. The document was not circulated amongst those in attendance, yet its main contents were briefly explained..$^{13}$ It is relevant to recall the recollections of some of those who attended this presentation, which was also the last ever meeting at Liliesleaf. Within five days the farm would be raided.

Bob Hepple recalled that the meeting became extremely heated. He recollected Govan Mbeki as being enthused by the Peasants Revolt in the Eastern Cape and Sekukuniland. Mbeki pushed the plan and, "was gung ho for it". ${ }^{14}$ Hepple was aware that Raymond Mhlaba and Joe Slovo supported the plan. ${ }^{15}$

Joe Matthews shared Hepple's sentiment about the plan's other author. Slovo was in Matthews's view, "a bit of a romantic. He even preached a very interesting idea which I think was not really correct that you could even before the objective conditions existed, you could go ahead with an armed struggle. That of course is an idealist position. But he got that from Che Guevara, you see. Che Guevara's book of guerilla warfare suggested that a leadership could create a climate in which eventually armed struggle could flourish, even before the conditions existed for such an armed struggle."16

About Operation Mayibuye, Hepple's thoughts were that it was, "a crazy plan which would provoke brutal repression and set back by years what I regarded as the main task that of building up of effective political and trade union organisation among the people. This was not Che Guevara's Cuba but a highly armed state, supported by the white population, and backed by the USA as part of its global strategy against Russia. A military operation of the kind envisaged had no hope of success and would entail untold suffering."17

12 Ibid., pp. 140-141.

13 B Hepple, Young man with the red tie: A memoir of Mandela and the failed revolution: 1960-1963,<https://www.amazon.com/Young-Man-Red-Tie-Revolution-ebook/dp/ B00EZM7PUW/ ref=mt_kindle?_encoding=UTF8\&me=>, assessed 24 March 2017.

14 LL/INT 3/Lot 4/Tran 1. G Benneyworth interview with Sir Bob Hepple, 2006.

15 Hepple.

16 SADET, p. 141.

17 LL/INT 3/Lot 4/Tran 1. G Benneyworth interview with Sir Bob Hepple, 2006. 
Hepple recalled that Bernstein had, "serious political objections" and was of the view that, "we were not ready for this yet and that these discussions needed to be further pursued"..$^{18}$ Bernstein, according to Hepple, made the most detailed political critique. His view was that the plan was founded on a mistaken analysis of the balance of power in South Africa and the strengths and weaknesses of the government and the movement. ${ }^{19} \mathrm{He}$ put forward an alternative motivation for, "limited guerilla activity from the High Commission Territories, Bechuanaland and so on; raids into South Africa, escaping back there. He said that would lead to an international incident, would involve other powers and be an important catalyst." 20

As for Bram Fischer, Hepple confirmed in 2005 that Fischer, "opposed it on pragmatic grounds. He said it would bring down a reign of terror. It would lead to mass arrests and we would destroy everything. He was strongly opposed to it." ${ }^{11}$ Hepple further related that Fischer, "was incandescent that Slovo and Marks had not obtained internal sanction before their departure to lobby the plan to the external leadership". ${ }^{22}$ Sisulu was equivocal that guerilla warfare was not a feasible option.

Kathrada was opposed to the plan. He supported Hepple's view that, "Operation Mayibuye was never ever passed by anybody. The Central Committee had grave reservations about it, and the High Command never approved it." ${ }^{23}$ Kathrada recalled in 2004 that on paper Operation Mayibuye looked like a very advanced revolutionary document, yet he remained skeptical. "They talked of ships landing on the Zululand coast with masses of ammunition and arms to be transported from Natal, from the Zululand coast, by road to some mythical farm where it was going to be stored. Seven thousand volunteers, MK didn't even have two hundred people in training."24 Kathrada agreed with the political objections raised by Bernstein and the practical ones by Fischer. It would provoke a wave of brutal repression and set them back by years when the main task was to build up effective political and trade union organisation amongst the people. ${ }^{25}$

Andrew Mlangeni, a Rivonia trialist, recounted that, although being a latecomer to Liliesleaf, he was part of the debate and that when he arrived there he, "found this document, we went through it, I remember, with Albert Mthembu, we accepted portions of it, not the entire document. There were other portions of the document which we thought could not be implemented, but my own personal point of view, three quarters were accepted, and one quarter was not

18 Ibid.

19 Hepple.

20 LL/INT3/Lot 4/Tran 1. G Benneyworth interview with Sir Bob Hepple, 2006.

21 Ibid.

22 LL/INT 3/LOT 4/Notes 1. G Benneyworth interview with Sir Bob Hepple, 2006.

23 LL/INT 2. G Benneyworth interview with Ahmed Kathrada, 2006.

24 Ibid.

25 Hepple. 
accepted. And what happened was in fact they wouldn't allow me to leave this place. If you wanted to study and read it, you had to come here. Read it, make your comments." 26

When asked in 2004 if Nelson Mandela had ever seen the document, Kathrada responded, "No he didn't see the document, not before his arrest". ${ }^{27}$ Goldreich's view was that something had to be in place to act as a starting point. "I think that no one ever thought, amongst us certainly, that Operation Mayibuye was a logistics program or a plan or a tactical document. It was a step towards something, and I knew that towards something mattered, as Denis has said, it was towards military action."28

Denis Goldberg remembered Operation Mayibuye as a concept, but one that was never implemented; it was a plan in the process of being created. "Whether it would have worked or not, we can never know, we can't go back. We had discussed it in our Logistics Committee, and we had expressed doubt about many of its aspects. I took the view that this would be sorted out at the political level. But we'd seen Operation Mayibuye, we'd read through it together. We knew it was being discussed to try and finalise it. I also knew, as I told you, that there were some who were pushing hard for a total military solution and to hell with the politics, and others who were demanding that politics were on top, and I supported that view, which is why I was surprised when Joe Slovo left on the assumption that the plan had been adopted. But you can't go abroad and talk about training camps and weapons supplies unless you do go and say it's adopted. So you create the conditions. It's not unnatural for people to have different views of a meeting. That's why you have minutes and people argue about them afterwards." ${ }^{29}$

\section{REPUBLICAN INTELLIGENCE}

By 1963 Operation Mayibuye, like Radio Freedom, formed a key intelligence need for a relatively unknown organisation at that time, called Republican Intelligence $(\mathrm{RI}) .{ }^{30}$ Radio Freedom was radio transmissions that were illegal and operated on a covert and underground basis. It later became the voice in exile for the liberation movements. This secret intelligence unit was separate to the Directorate of Military Intelligence which was responsible for intelligence since the formation of the Union of South Africa in 1910 and the Security Branch of the South African Police. RI was the forerunner of the Bureau of State Security

26 LL/INT 2. G Benneyworth interview with Andrew Mlangeni, 2004.

27 LL/INT 2. G Benneyworth interview with Ahmed Kathrada, 2006.

28 LL/INT 2. G Benneyworth interview with Arthur Goldreich, 2004.

29 LL/INT 2. G Benneyworth interview with Denis Goldberg. 2004.

30 LL/G Benneyworth of Site Solutions (c) Appendix C, Part 1. Interviews undertaken separate to 2005 Audit, APC 1: Interview with Gerhard Ludi. 
(BOSS), which was later re-engineered by PW Botha and Niel Barnard into the National Intelligence Service (NIS) and, with the transition in 1994, the NIS in turn split into the National Intelligence Agency (NIA) and the South African Secret Service (SASS). More recently, this changed again into the State Security Agency.

On 14 January 1963, following the conviction of Nelson Mandela, General Hendrik van den Bergh was appointed as head of the South African Police Security Branch with instructions to reorganise the security establishment of the Republic. Van den Bergh created Republican Intelligence and it became operational during the first quarter of 1963. One of the needs of the South African government was an intelligence organisation that could trade information with foreign powers, recruit African spies and journalists and perform an intelligence function along the lines of the American Central Intelligence Agency $(\mathrm{CIA})$ and Britain's Secret Intelligence Service (SIS). RI, together with the Security Branch, was tasked with smashing all organised resistance to the apartheid regime. The mass arrests of the Pan African Congress's (PAC) POQO uprising in the Cape during April to June 1963, followed by the Rivonia raids and trial and the capture of the Second High Command and Bram Fischer, sequenced into this period of activity by RI.

Colonel Johann Coetzee was appointed as Rl's operational head along with Mike Geldenhuys and other agents, such as Gerhard Ludi, with offices in Commissioner Street, Johannesburg. During these early days their office space was at a premium - the agents had to roll up the carpet to allow visitors in through the door. The Minister of Justice, BJ Vorster had little to do with the department, other than to sign off its finance bills. ${ }^{31}$

RI had as its primary focus the SACP. Gerhard Ludi, one of the Rl's first agents, has suggested that a prior suspicion existed within the security establishment that the Party was the core of the problem confronting the apartheid regime. Who exactly determined this assessment remains unknown. Yet it is worth noting that RI was assisted by the CIA who provided intelligence about the financial assistance Russia was providing to the African liberation movements. The CIA also apparently indicated who the KGB operatives in South Africa might be and pointed out some of the local communists to $\mathrm{RI} .{ }^{32}$

$\mathrm{RI}$ created a list of formerly identified communists who had been active above ground as far back as the 1940s before the Party was banned. "The feeling was that if one learned about the cores of the Communist Party one would learn about the why and where and the role the Soviets were playing in this". ${ }^{33}$ Consequently the who's who of the SACP would form the focus for the initial RI operations.

31 LL/G Benneyworth of Site Soultions@ Appendix C, Interview with Gerhard Ludi.

32 Ibid.

33 Ibid. 
RI did not have to look very far. Many of these people who played important roles in the Party were known. Govan Mbeki, Raymond Mhlaba, Michael Harmel, Lionel Bernstein, Hilda Watts, Harold Wolpe, Ahmed Kathrada - the list is extensive when one considers all the former listed and banned members of the Communist Party. Ludi has mentioned that Mhlaba, Bernstein and Harmel were individuals who would receive special attention by RI. Given their relationship with Liliesleaf and the underground structures, this could have serious ramifications for the movement.

Sharing intelligence formed part of the operational modus operandi. RI fed intelligence to both the CIA and the SIS on a weekly basis. Presumably this was not a one sided relationship and these agencies reciprocated. For example, Captain Herbert Bartaune operated an air charter company, called Bechuanaland Air Safaris, which played a key role in the logistics route for MK and the liberation movements between Bechuanaland, Tanganyika and Zambia. This was a front company set up by the British SIS and is also known in the literature as the pipeline ${ }^{34}$ However it's Managing Director, Captain Bartaune, was a multiple agent, providing information to the South African Security establishment, British intelligence and possibly the $\mathrm{CIA} .{ }^{35} \mathrm{He}$ flew Nelson Mandela within days before he was captured.

This foreign intelligence feed also included information about Operation Mayibuye. Bits and pieces of information flowed into Rl over quite a period of time. Yet, until the Liliesleaf raid RI never managed to obtain sufficient intelligence to constitute a total understanding of Operation Mayibuye. By 1962, Gerhard Ludi had successfully infiltrated the SACP. According to Ludi, he was sent to Russia to spend a substantial amount of time there. The KGB apparently liked him and spent time working with him. Through this process and also from other agents that he controlled in the Party, Ludi obtained quite a bit of information about Mayibuye as the "bits and pieces" of information flowed in. ${ }^{36}$

The exact nature of the information about Operation Mayibuye which RI obtained remains unclear. However, Ludi mentioned the following points in an interview; so these may have included how the movement was going to implement the operation, the military fronts that they were going to establish, and the tactics that they were going to use. ${ }^{37}$

Ludi recalled that the plan was seized at Liliesleaf and that it confirmed information that RI had already obtained and understood. He described this seizure as being, "beautiful to have all these bits and pieces suddenly

34 G Benneyworth, "Bechuanaland's aerial pipeline. State surveillance, repression and counter-insurgency, 1960-1965". Paper presented at The Politics of Armed Struggle in Southern Africa Conference, Johannesburg, 24 November 2016.

35 National Archives of United Kingdom (hereafter NAUK), FO 371/167528, South Africa: Export of Arms to South Africa: Smuggling and Gun-running Activities, 1963.

36 LL/G Benneyworth of Site Solutions@ Appendix C, Interview with Gerhard Ludi.

37 Ibid. 
[making] sense in one document but it was nothing really new but just put into perspective" ${ }^{38}$ Within a few days after the raid, a group of RI agents, including Ludi, were driven to Liliesleaf under cover of darkness late one night. There he found the farm crawling with police who were busy searching the buildings. Ludi recalled that they were finding things under the floorboards and inside the chimneys. His reference to chimneys is worth remembering; the farm only had two chimneys, one inside the main house and another connected to a fireplace inside the thatched cottage.

Ludi recalled that the police had masses of documents laying everywhere and that they gave him and RI copies of Operation Mayibuye, together with other documents which he described as being of tremendous importance. The police asked RI to study these documents and to provide comment. Ludi described being shown a bomb room and was asked if he recognized any of the materials as being similar to the stuff that he had seen in Russia. He replied that he did not, claiming it was meaningless to him. He was disappointed; he had wanted to see the radio transmitter as this had formed a separate focus for a prior RI operation, but it had already been taken away. ${ }^{39}$

\section{HOW MANY COPIES OF OPERATION MAYIBUYE EXISTED?}

To date it is widely assumed that only two copies of Operation Mayibuye existed at the time of the Liliesleaf raid: the copy with Slovo and another copy which was seized by the police on a table inside the thatched cottage or from within a chimney pipe in the cottage.

However, at least three copies existed; two of which were at Liliesleaf when the police struck and another with Slovo, who was out of the country. The possibility that a fourth copy existed cannot be ruled out. This article will show that the police manipulated the evidence to suggest that there was only one copy at Liliesleaf, which may have in turn contributed to the confusion which still prevails about the number of copies that existed. It is also important to remember that the content of all three copies may not have been identical at the time of the raid, given that only one copy is known to have survived and that it was still a work in progress

As for the other two copies: Copy Two was under discussion inside the thatched cottage and Copy Three was concealed behind a hubcap on Goldreich's Citroen. A fourth copy may have been with Wilton Mkwayi when the raid struck on 11 July 1963. This numbering of the copies as one, two and three

\footnotetext{
38 Ibid.
}

39 Ibid. 
is purely for sequential purposes and is not drawn from any evidence lists, nor does it reflect any hierarchy of importance.

\subsection{Copy One}

This copy left South Africa with Slovo in June 1962. Slovo was accompanied by JB Marks. His task was to consult with Oliver Tambo and the external leadership about Operation Mayibuye. The two arrived in Lobatse on 2 June $1963 .{ }^{40}$ Their movements and activities were being monitored by more than one intelligence organisation, namely the British Intelligence and the South African Intelligence.

South Africa's Department of Foreign Affairs, through its Kenya Embassy, obtained a copy of an East African Airways flight manifest dated 21 June 1963. This manifest for a flight between Francistown and Dar es Salaam listed 28 passengers, all described as South Africans and included Slovo and Marks. ${ }^{41}$ Consequently, the possibility that South African agents operating inside Bechuanaland had also located Slovo and Marks cannot be ruled out. As for Britain's SIS, it too had locked on to the pair. One of its sub-agencies, the Bechuanaland Intelligence which fell within the structures of the British Security Services, tracked them from the moment they entered Bechuanaland until their departure on 21 June 1963.

Bechuanaland Intelligence sources differ on the nationality of the passengers on the South African obtained manifest. They described the other passengers as being 24 ANC and two South West Africa People's Organisation (SWAPO) refugees and that, while this was an East African Airways flight, it was specifically chartered for the purpose of airlifting these "politicals". ${ }^{42}$

With respect to the flight, the Secretary of State for the Colonies indicated that their London Office was approached by one Kyaruzi, the Permanent Secretary, Ministry External Affairs, "for help in getting refugees to Tanganyika". ${ }^{43}$ The Secretary further stated that it was understood to be 28 refugees who were mostly students, but that difficulty was experienced in finalising the airlift. WNELA, who owned the airport, had refused permission for the East African Airways flight to land on the provisionally agreed date of 22 June 1963 before departing with the passengers the following day. The Tanganyika authorities were described as being grateful if the British and Bechuanaland authorities could help in securing these landing rights. ${ }^{44}$

40 NAUK, CO 1048/586: CONFIDENTIAL. Inward Telegram to the Secretary of State for the Colonies, 17 June 1963.

41 National Archives of South Africa (hereafter NASA), BTS 109/6, Vol. 3.

42 NAUK, CO 1048/586: CONFIDENTIAL: Outward Telegram from the Secretary of State for the Colonies to BBS South Africa, 18 June 1963.

43 Ibid.

44 Ibid. 
The Resident Commissioner of Mafeking finalised the issue. On 18 June 1963 he requested WNELA to give landing clearance. WNELA was the recruiting corporation for South Africa's Chamber of Mines and used the airstrip to transport migrant workers to mining compounds. ${ }^{45}$ Of interest is that the Commissioner described the group of refugees as being a "corrupt group", presumably a reference to Slovo and Marks and possibly others who were engaged in activities that were non-student related. ${ }^{46}$

That Slovo and Marks were a focus of British Intelligence is not in doubt. A communication dated 7 June 1963 from the British Embassy in Cape Town to the West and Central African Department in the Foreign and Colonial Office London reporting their arrival in Bechuanaland refers, "As these people will be well known in London and are close colleagues of the Hodgsons and Harmel, a further report will be made in due course to the Colonial Office." ${ }^{47}$ Another report indicates that Slovo was under surveillance. "Slovo whilst in the territory visited the Hodgson's and there is reason to believe that he discussed airlifts for refugees from South Africa via Bechuanaland Protectorate to Tanganyika for sabotage training". ${ }^{48}$ This information about discussions between Slovo and Hodgsons was fed into the Bechuanaland Intelligence apparatus by, "a delicate but reliable source". 49

The possibility exists that, had Slovo discussed Operation Mayibuye with the Hodgsons, their conversation was overheard, witnessed or intercepted by this delicate source who, in turn, fed this information into Britain's intelligence network. That the Hodgsons and Harmel were under direct surveillance since their arrival in Bechuanaland has also been established from other British based archival records. Bechuanaland Intelligence quoted Marks as stating in a press release carried by the Bulawayo Chronicle that, "communist financed warfare will start in the Republic within the next two years", and that, "we also have access to modern weapons". ${ }^{50}$ Marks was further reported to be on route to Peking at the invitation of the Chinese government. ${ }^{51}$

45 L Callinicos, Oliver Tambo: Beyond the Engeli Mountains, (Cape Town: David Phillip Publishers, 2004), p. 261.

46 NAUK, CO 104/586: CONFIDENTIAL: Inward Telegram to the Secretary of State for the Colonies from BBS South Africa, 18 June 1963.

47 NAUK, CO 1048/586: RESTRICTED: 10131/48, 7 June 1963.

48 NAUK, CO 1048/586: SECRET: Inward Telegram to the Secretary of State for the Colonies from Resident Commissioner Bechuanaland, 8 July 1963.

49 NAUK, CO 1048/586: SECRET: Submission to Ministers.

50 NAUK, CO 1048/586: SECRET: Inward Telegram to the Secretary of State for the Colonies from Resident Commissioner Bechuanaland, 8 July 1963.

51 Ibid. 
Immediately after the two flew out, the Bechuanaland Executive Council declared them both prohibited immigrants to the Protectorate. ${ }^{52}$ The Bechuanaland authorities categorised them as being in the same vein as Patrick Duncan, another prohibited immigrant. Marks's statements, "associated himself with a policy of organising violence in South Africa" and that both Marks and Slovo were "selfconfessed communists". ${ }^{53}$

Given that intelligence was shared between South Africa's Republican Intelligence Department and the British and Americans on a weekly basis, it seems likely that America's CIA, Britain's SIS and South Africa's RI and possibly its other security agencies of military intelligence and the SA Police Security Branch were functioning within a co-operative loop, monitoring Slovo and Marks and possibly the content of their mission. ${ }^{54}$

Perhaps at least one of these agencies retraced their steps and consequently linked at least Slovo to Liliesleaf, given that he departed from the farm. Mac Maharaj recalled being accompanied by Ruth Slovo and driving down the Liliesleaf driveway where they encountered Joe Slovo driving up the driveway. Both Maharaj and Ruth Slovo were until then under the impression that Joe had already left the country, yet they exchanged farewell pleasantries..$^{55}$ Such a surveillance operation was possible given that Slovo's activities were being monitored in South Africa. The RI would have certainly have had him in their sights; after all he was a listed communist.

\subsection{Copy Two}

Copy Two was inside the thatched cottage when the raid commenced. This fact has been sufficiently documented, not only in the Rivonia Trial court record, but also in various publications and, as a result of interviews with those present in the thatched cottage, by historians and researchers over the years. Assuming that the police found Copy Two, they would have retrieved it from inside the coal stove. No one had removed it from the cottage or the stove before Detective Kennedy burst inside.

Copy Two is of specific interest and is, in turn, linked to Copy Three. Govan Mbeki recalled that he stuffed the document into the stove with the aim of burning it when the police and their barking Alsatian leapt from their van between the cottage and the main house. Mbeki wasn't carrying matches as he had recently stopped smoking. He called around for matches, but Walter Sisulu said he couldn't destroy the document. Mbeki left it there and together with Sisulu and Kathrada they jumped through a rear window and attempted to escape, but

52 NAUK, Para 157 of CIC Report No 6/1963: As Contained in Secret Central Intelligence Committee Report No 7 of July 1963, (Bechuanaland Intelligence).

53 NAUK, CO 1048/586: SECRET: Submission to Ministers.

54 LL/G Benneyworth of Site Solutions@), Appendix C, Interview with Gerhard Ludi.

55 L/INT 8/Notes 1. G Benneyworth interview with Mac Maharaj, 2005. 
were captured by the police. Logic suggests that they were then escorted around the building towards the vans and never re-entered the thatched cottage again. As for the remaining three inside, Lionel Bernstein, Raymond Mhlaba and Bob Hepple, Kennedy promptly arrested them. They were then escorted outside.

This poses the first question: where inside the stove did Mbeki attempt to hide the document; within its fireplace area or inside the chimney pipe itself?

Bernstein recalled someone screwing up the document, placing it in the fire place and trying to light it. Although not in the cottage at the time, Elias Motsoaledi stated that he thought that it was shoved up the chimney. Hepple further corroborates this, "Mbeki collects the 'Operation Mayibuye' document and some other papers and I see him putting them in the small stove in the room". 56

This presents the first anomaly and direct evidence that the truth surrounding any Operation Mayibuye document found at Liliesleaf was about to be distorted by the police. They took photographs of the crime scene which reflect two points of focus, namely to record the spaces within which they found evidence and to link these photographs and evidence to evidence lists that were created on the scene of the crime.

Their photographs of the various other storage facilities, such as the two coal sheds and the outbuilding interiors, depict the spaces and their linkage to the evidence as forming the primary focus point for the photographer. However, in all the police photographs taken inside the thatched cottage the coal stove is not visible.

Instead, the photographer focused on three separate paper items lying on the table: a newspaper article, a Government Gazette and a stack of blank papers. Operation Mayibuye is nowhere to be seen. The police subsequently claimed that they found the plan on the table and misled the court to this effect. Yet, they admitted to Bob Hepple during his detention that, "We know you hid Operation Mayibuye in the chimney. You were part of this". ${ }^{57}$

Which poses the primary question, why lie about where it was found and why not photograph the correct spot, namely the stove as opposed to the table?

\subsection{Copy Three}

The author's research has established that two meetings were to take place at Liliesleaf on the day of the raid: a meeting of the Secretariat inside the thatched cottage and a meeting of the Logistics Committee in the dining room inside the main house later that night, probably after dinner. Wilton Mkwayi chaired the Logistics Committee, which included Arthur Goldreich, Ian David Kitson, Hilliard Festenstein and Lionel Gay. Denis Goldberg was at Liliesleaf when the raid commenced as he was required at the Logistics Committee meeting.

\footnotetext{
56 Hepple.
}

57 Ibid. 
Ian David Kitson had Copy Three with him at his home; but, ill with flu, he was unable to attend the meeting. Consequently, Arthur Goldreich stopped at Kitson's home to collect this copy since it was required at the meeting. Goldreich hid the copy behind a hubcap on his Citroen and drove into Liliesleaf where he was arrested after parking his car in front of the garage. The police immediately screwed off his hubcaps and retrieved the copy. ${ }^{58}$ This, in turn, presents the second anomaly concerning the Operation Mayibuye plan.

The evidence lists compiled by the police at the crime scene and later entered into the court record during the Rivonia Trial make no mention of any copy of Operation Mayibuye being found behind any hubcaps or anywhere else on or within Goldreich's car. In fact, all the evidence lists only mention one copy being found at Liliesleaf; the copy inside the thatched cottage on the table. Yet, Goldreich witnessed this copy being retrieved from behind his hubcap from where he concealed it.

Furthermore, the police photographic collection taken at Liliesleaf reveals that Goldreich's car was not photographed, unlike other vehicles on the farm that day, despite the fact that the police claimed to have found 31 individual items and incriminating documents inside his car and, according to Goldreich, the most explosive document of all, a copy of Operation Mayibuye behind a hubcap. However, it cannot be ruled out that the police did in fact photograph the car, but subsequently buried this photograph; hence its disappearance after Goldreich had escaped from South Africa.

Given that Goldreich wouldn't be standing trial and that he was the only person to witness them screwing off the hubcaps and finding the document, this presented the police with an opportunity to manipulate the evidence and fabricate the truth surrounding the Logistics Committee's copy of Operation Mayibuye.

A review of the evidence lists implies that Goldreich was extremely reckless, driving around Johannesburg with all this incriminating material tucked away in the boot of his car. However, this is unlikely, given that Goldreich went to great trouble to conceal the document behind the hubcap. Instead, the hypothesis is that the police tampered with the crime scene by spreading evidence which they found into every nook and cranny at Liliesleaf and in every possible way in order to incriminate key people and to besmirch the reputations of the ones who got away.

So what happened to this copy and, for that matter, what are the implications surrounding the copy that was shoved into the stovepipe chimney inside the thatched cottage?

58 LL/INT 2. G Benneyworth interview with Arthur Goldreich, 2004. 


\section{CONCLUSION}

Govan Mbeki shoved Copy Two into the stovepipe chimney. In doing so, the document was marked with soot which is virtually impossible to remove from white paper once such staining has occurred. The police found the document and retrieved it only after they had photographed the inside of the thatched cottage, probably the following day or a few days later when RI agents arrived. South African law required that a property occupant had to witness a police search for and retrieval of evidence on a property. This is why Goldreich was photographed witnessing the excavation of a cable from behind the outbuildings and this poses the possibility that he was also photographed witnessing their search of the coal shed. However, if it existed, the photograph has since disappeared.

However, Goldreich was not present when they pulled out the soot stained copy from the stovepipe chimney. Consequently, the police were faced with a dilemma. Although they had captured six operatives busy meeting inside the cottage, they had seized neither notes nor minutes of what was being discussed. They had a copy of the plan, yet stained with soot. It was obvious where this originated. The accused could offer the defence that, as it was retrieved from a fireplace or chimney, they had never seen the copy before. If they put this argument across strong enough, who could dispute it and who knows how a judge may have reacted.

Furthermore, entering the soot stained copy into evidence might have opened up another can of worms; the police might be accused of incompetence. They had not photographed its retrieval from the chimney and their only crime scene photographs depict the table and other angles facing away from the fireplace inside the cottage.

The risk was just too great. The state had bungled once before with the Treason Trial and Detective Sergeant Dirker, who drew up the crime scene evidence lists and was present when the photographs were taken had also been humiliated for his bungling of prior political cases. For example, the drubbing he received at the hands of Harold Wolpe during a litigation case brought against him by Michael Harmel earlier that same year and which he lost. ${ }^{59}$

The hypothesis is that the soot stained copy is not the copy originating from the cottage and thus entered into evidence. An examination of a copy of the document suggests that it was not marked with soot when entered into court evidence. The hypothesis is this is what transpired:

Dirker was both devious and dangerous and not averse to fabricating evidence. Either he or another unidentified policeman took the clean copy which they retrieved from behind Goldreich's hubcap and then later claimed to have found it on the table. They could not say it originated from the stove. Otherwise

59 NASA, WLD/ Ref 5958, M Harmel versus Dirker. 
the defence could argue that it wasn't stained with soot. Pinning the document on Goldreich who had escaped and would not face trial would be a waste of a most explosive piece of evidence which constituted political dynamite. Consequently, they could attach it to the six captured inside the cottage and claim that, since it had literally been tabled for discussion that day, it should hang them all. Copy Three over the last 53 years was therefore misunderstood to be Copy Two. 